\title{
Role of Ultrasonographic Measurement of Fetal Head Circumference in the Evaluation of Gestational age in Bangladeshi Women.
}

\author{
Sharma NK ${ }^{1}$, Dey $\mathrm{SN}^{2}$, Rahman $\mathrm{MM}^{3}$, Zahan $\mathrm{A}^{4}$, Islam $\mathrm{M}^{5}$, Mukthadira ${ }^{6}$.
}

\begin{abstract}
Determination of gestational age by ultrasound has now become an integral part of maternal antenatal care. Accurate assessment of gestational age by sonography is now essential for obstetric management particularly due to term, preterm and post date management. Timing of elective caesarean delivery and decision whether to consider a fetus at risk for intrauterine growth retardation depends in part on the estimated age. In this study gestational age was determined on the basis of head circumference $(\mathrm{HC})$ and correlation was established between weeks of gestation calculated from LMP. A cross sectional study was carried out in the department of Radiology \& Imaging, Mymensingh Medical College Hospital during the period of January 2011 to June 2012. Three hundred ninety seven normal pregnant Bangladeshi women age range from 20 to 36 years with apparently healthy fetuses between 18 to 38 weeks of gestation referred for ultrasonic evaluation of pregnancy profile. Mean age was 29.60 years with standard deviation (SD) +0.67 . Aim of this study was to determine relationship between menstrual age and $\mathrm{HC}$. Result of this study may give idea about gestational age calculated by LMP of 397 cases and expressed in weeks. Estimated gestational age was determined by HC evaluated by US and expressed in weeks. Significant positive correlation was found between gestational age measured by HC and LMP. Estimated gestational age measured by HC had very close relation with weeks of gestation(LMP), which is 2 to 3 days less from weeks of gestation (LMP) during 18-38 weeks of gestation variation was only 2 to 4 days less from weeks of gestation (LMP). A strong positive significant correlation $(r=0.987, P<0.001)$ was found between weeks of gestation and predicted gestational age measured from $\mathrm{HC}$. Significant relationship between gestational age measured by LMP with estimated gestational age evaluated by head circumference.
\end{abstract}

Key words: Head circumference, Ultrasonography, gestational age.

CBMJ 2017 July: Vol. 06 No. 02 P: 06-11

\section{Introduction}

Diagnostic ultrasound is a well-established, effective which employs the use of high frequency ultrasound waves for imaging. Ultrasound is the best and safest modality to obtain information about fetus and its environment directly. Determination of gestational age by ultrasound has now become an integral part of maternal antenatal care. ${ }^{1}$ Now a days, in Bangladesh, ultrasound is also available in Upazilla level. So it is readily available, less expensive modality for detection of gestational age accurately.

Various parameters have been proposed to establish gestational age by ultrasound. These include gestational sac size(GS), crown rump length(CRL), biparietal diameter (BPD), head circumference $(\mathrm{HC})$, abdominal circumference (AC), fetal long bones, binocular distance, size of fetal kidney etc. However the most popular method still remained the estimation of gestational sac size, CRL, BPD, HC, $A C$ and femur length. ${ }^{2}$
1. * Dr. Netay Kumer Sharma

Assistant Professor

Department of Radiology and Imaging

Community Based Medical College Bangladesh, Mymensingh.

2. Prof. Dr. Sankar Narayan Dey

Professor

Department of Radiology and Imaging.

Community Based Medical College Bangladesh, Mymensingh.

3. Prof. Dr. Md.Masudur Rahman Professor

Department of Radiology and Imaging,

Community Based Medical College Bangladesh, Mymensingh.

4. Dr. Akter Zahan

Associate Professor

Department of Gynae \& Obs

Community Based Medical College Bangladesh, Mymensingh.

5. Dr. Mahzabeen Islam

Associate Professor

Department of Radiology and Imaging

Community Based Medical College Bangladesh, Mymensingh.

6. Dr. Mukthadira

Assistant Professor

Department of Radiology and Imaging

Community Based Medical College Bangladesh, Mymensingh.

*Address of correspondence

Mobile: +8801711962023

E-mail : nksharma89dr@gmail.com 
Uncertain gestational age is associated with higher perinatal mortality and an increased incidence of low birth weight and preterm delivery. Gestational age in second and third trimester of pregnancy are usually calculated by measurement of biparietal diameter (BPD), femoral length ( $F L)$, head circumference $(\mathrm{HC})$ and abdominal circumference (AC). Accurate knowledge of gestational age is very important to deliver the fetus at risk and decision about timing and route of delivery. ${ }^{3}$

Literature is fraught with studies and tables to determine gestational age from various fetal parameters. We still do not have tables for determination of gestational age of fetus of our own population. For this reason, gestational age assessment is not so accurate, especially in the third trimester when the growth trend of fetus in our country is slower than that of western fetus. Therefore if we use their charts for age determination of fetus there is significant error in gestational age estimation and the fetus may appear small for date even when they are not. For this purpose this study was conducted, so that we would determine the gestational age of our fetus more accurately by using our own data. The obstetrical tables used in our country are produced from the data collected in the population of developed countries which may vary from our population. The most popular tables for measurement of obstetrical data in our country is Hadlock, Campbell, Tokyo, Hansemann, Osaka, Shephard etc. There is discrepancy among these systems which may be critical for the survival of an infant who has to be delivered early because of some antenatal complication.

For this reason this was designed to measure fetal head circumference in the evaluation of gestational age by using real time ultrasonogram in Bangladeshi women and also correlation with gestational age measured by LMP.

\section{Methods}

This present study was a cross sectional nonrandomized study. The study was carried out on 400 pregnant women aged 20-36 years from $1^{\text {st }}$ January 2011 to $30^{\text {th }}$ June 2012 reported to the department of Radiology \& Imaging ,Mymensingh Medical College Hospital for USG examination of fetal maturation assessment. Among them two cases presented with multiple pregnancy and one case with congenital anomaly. These three cases were excluded from the study. Hence the sample size was 397 for this study. Transabdominal ultrasonographic examinations were performed with supine position after proper preparation of the subject regarding the procedure with the help of departmental Toshiba SSA-325A ultrasound machine with a 3.5 or $5.0 \mathrm{MHZ}$ curvilinear transducer. Electronic calipers were used and all measurements were obtained in millimeters. Fetal biometric measurement included the $\mathrm{HC}$. Measurements of the $\mathrm{HC}$ obtained at the level of the falx cerebri interrupted by the septi pellucidi and the thalami. ${ }^{4}$ After informed consent was obtained, fundal height (in $\mathrm{cm}$ ) were measured. Then basic fetal measurements were taken to estimate the gestational age on the basis of Head circumferences measured by the scanner using formula that was incorporated into the scanner. I followed the sonographic parameters measured by filly \& Hadlock. ${ }^{5}$ The Transabdominal sonography was performed first by the investigator which then subsequently confirmed by a Radiology and imaging specialist of the department of Radiology and imaging, $\mathrm{MMCH}$.

Head Circumference was measured at a plane of section through the third ventricle and thalami with visualization of cavum septum pellucidum at the anterior portion of brain and tentorial hiatus at the posterior portion of brain. The calvaria is smooth and symmetric bilaterally. The cursors were positioned at the outer edge of the near calvarial wall to outer edge of the far calvarial wall. ${ }^{7}$ All relevant data were collected in a pre-designed data collection sheet, which included history taking with particular aspect relevant to this study, general examination, collection information about LMP, ultrasonographic findings, etc.

All the relevant collected data were complied on a master sheet first and then all data were 
checked \& edited carefully. Then data were entered into a computer. Analysis were done by employing statistical package for social science (SPSS Version 16.0) software package. An analysis was developed keeping in view the objectives of the study. The results were presented in tables, figures, diagrams, etc (shown on figure $1 \& 2$ ).

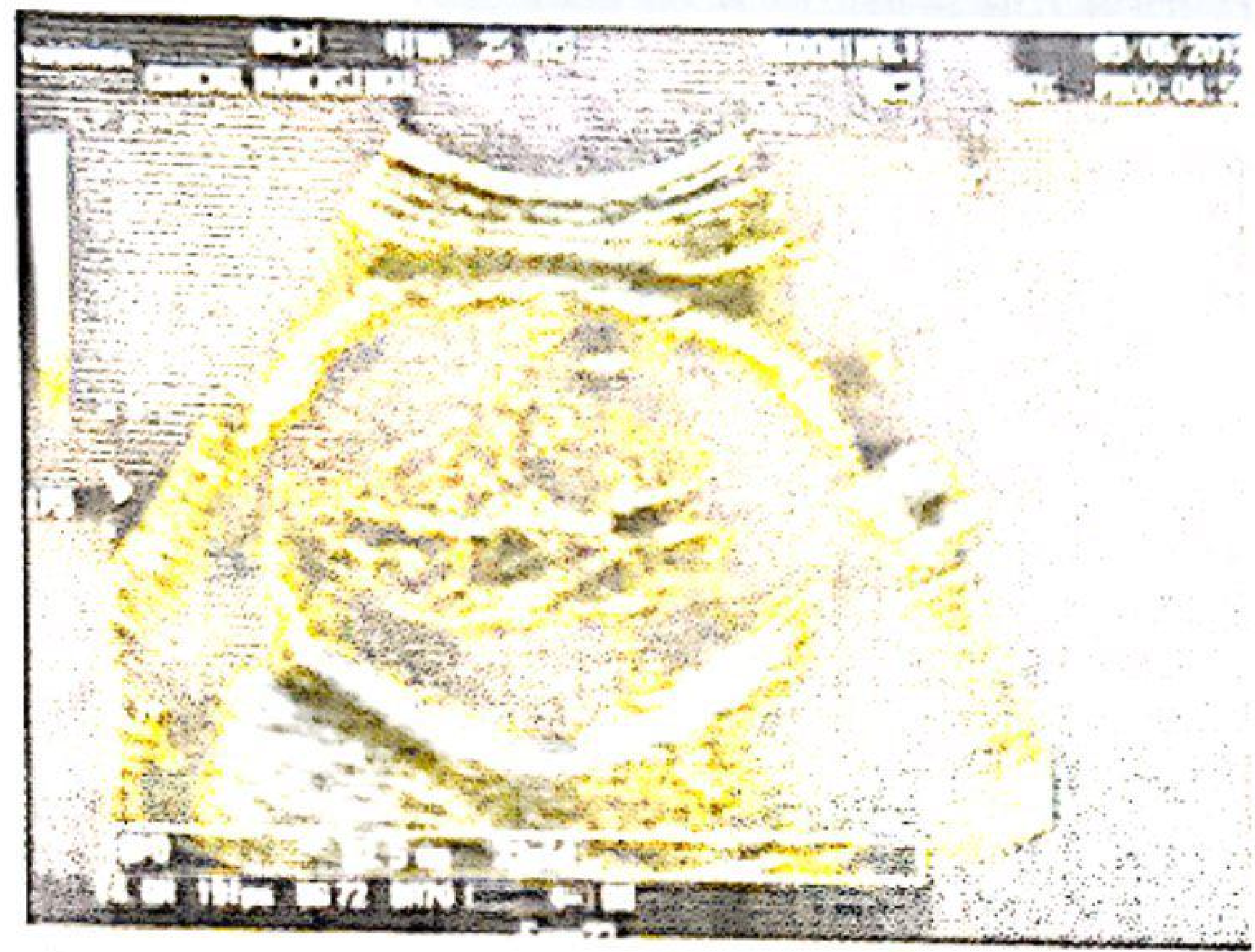

Fig 1 : Showing biparietal diameter measurement of a fetus of 32 weeks gestation (The cursors are positioned at the outer edge of the near calvarial wall to inner edge of far calvarial wall through the plane of section that traverses the third ventricle and thalami).

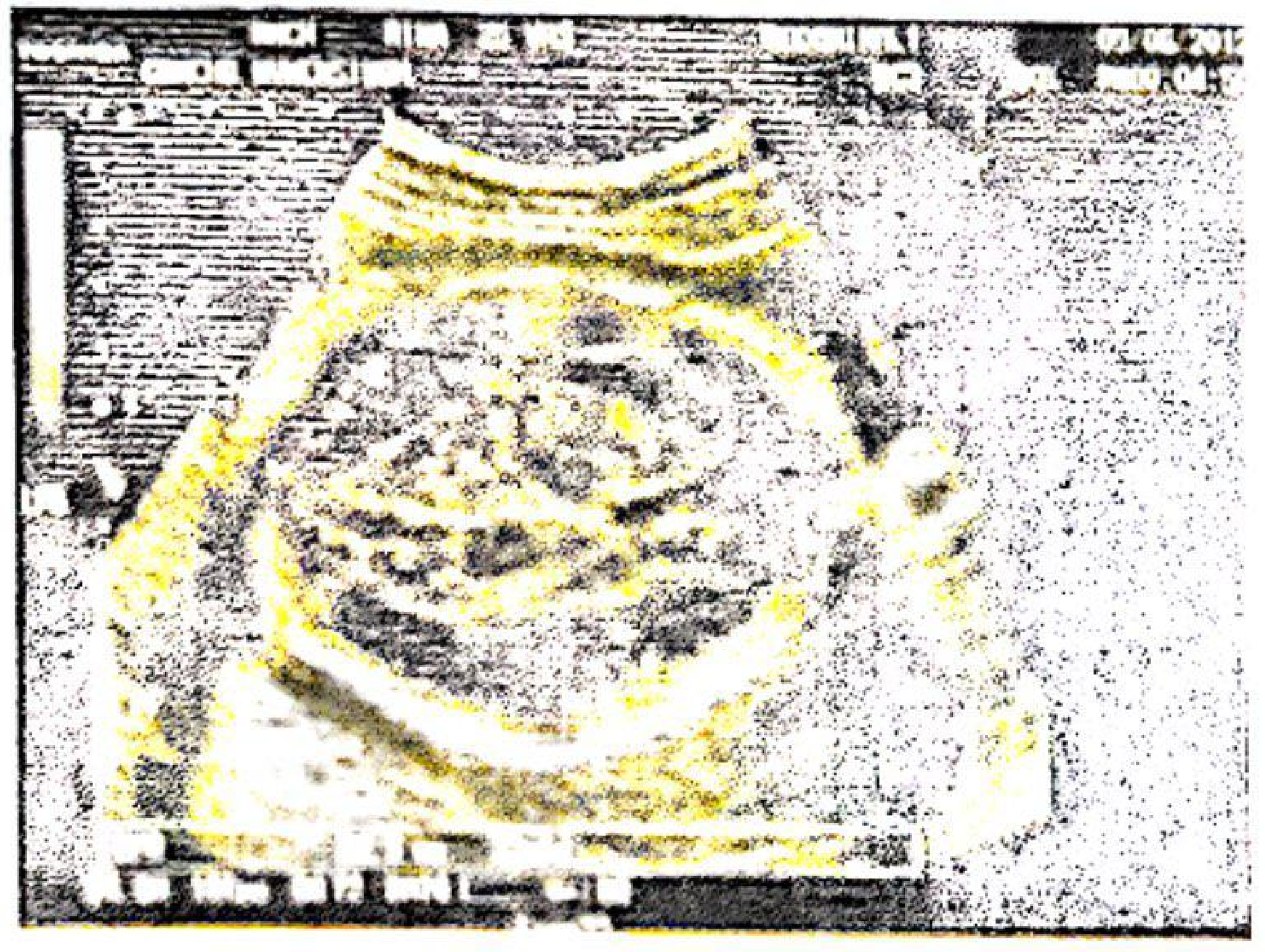

Fig 2: Showing head circumference measurement of a fetus of 32 weeks gestation (The calvarial is smooth and symmetric bilaterally.

The cursor is positioned at the outer edge of the near calvaria and outer edge of the far calvarial wall through the third ventricle and thalami).

\section{Results}

Three hundred and ninety seven subjects, after giving informed consent and with complete data were enrolled into this study. The age ranged from 20 to 36 years and the maximum number was found in the age group of 26-30 years. The mean age was 29.60 years with standard error of mean (SE) \pm 0.67 . The result is shown in figure 3 .

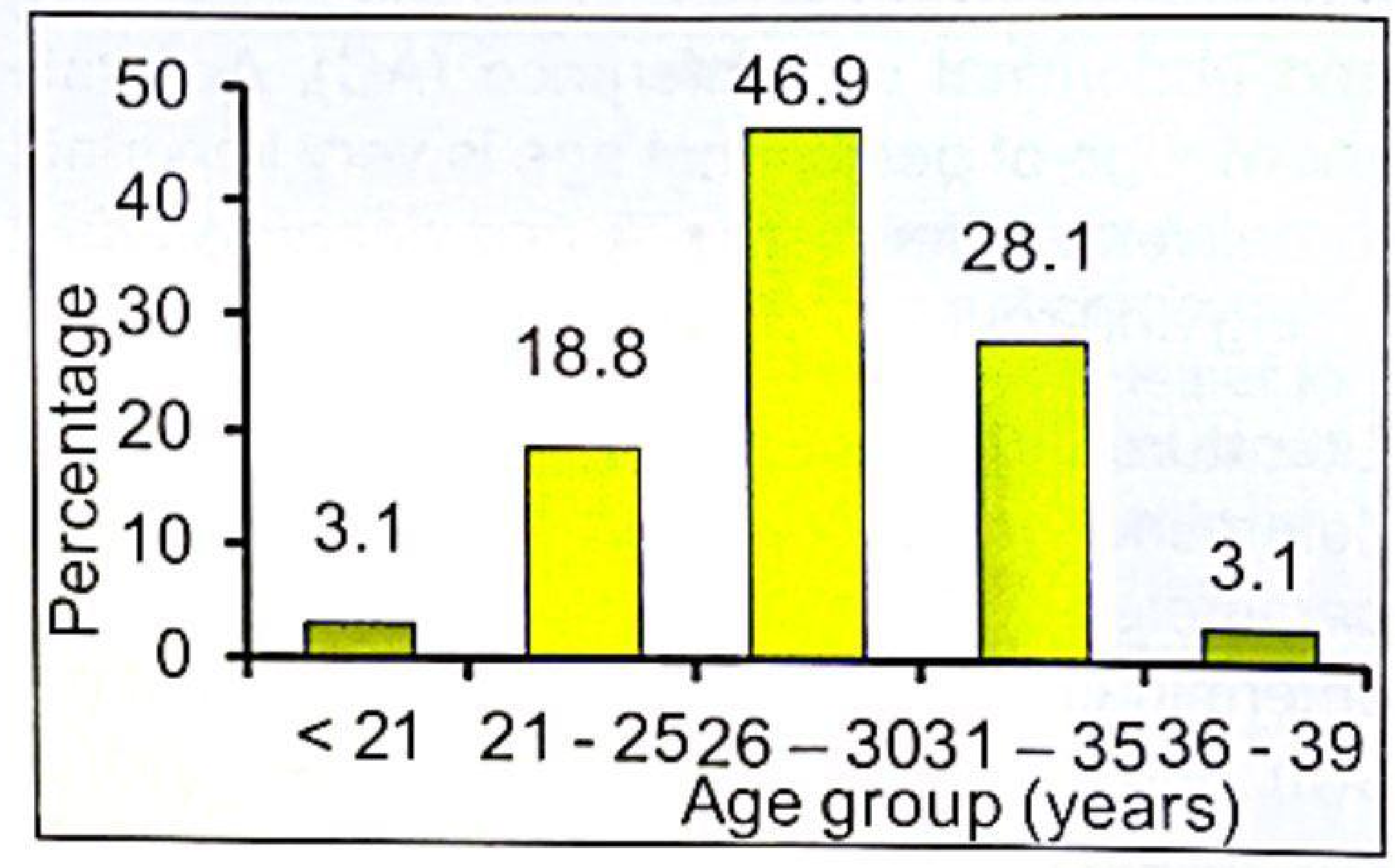

Fig 3: Bar diagram showing the age group of the study subjects $(n=397)$.

Distribution of the study subjects according to Gestational age $(n=397)$ : The mean gestational age was $27.5 \pm 5.8$ weeks with range from 18 to 38 weeks.

\section{Parity of the pregnant women:}

In this study out of 397 cases, 56.4 percent were primigravida, 33.3 percent were $2^{\text {nd }}$ gravida, 7.6 percent were $3^{\text {nd }}$ gravida, 3.1 percent were 4th and more gravida. Most of the cases were primigravida and $2^{\text {nd }}$ gravida. Distribution of the study subjects are shown on table I.

Table I: Distribution of the study subjects according to gravida $(n=397)$.

\begin{tabular}{|l|c|c|}
\hline \multicolumn{1}{|c|}{ Gravida } & $\begin{array}{c}\text { Number of } \\
\text { patients }\end{array}$ & Percentage \\
\hline Primiparas & 224 & 56.4 \\
\hline $2^{\text {nd }}$ gravida & 131 & 33.0 \\
\hline $3^{\text {rd }}$ gravida & 30 & 7.6 \\
\hline $4^{\text {th }}$ gravida \& more & 12 & 3.1 \\
\hline Mean $\pm S D$ & $1.6 \pm 0.9$ & \\
\hline
\end{tabular}

Head Circumference in this study: Table II shows summary of measurements of observed of head circumference $(\mathrm{HC})(\mathrm{mm})$, as a function of gestational age. Total number of patients was 397. The table gives the number of observation in each week, from 18 
to 38 weeks gestational age and $3^{\text {rd }}, 10^{\text {th }}, 50^{\text {th }}$, $90^{\text {th }}$ and $95^{\text {th }}$ percentiles, of head circumference at each week of gestation. It also gives the mean and \pm 2 standard deviations $( \pm 2 S D$ ) of the observed values. Table III shows the fitted $3^{\text {rd }} 10^{\text {th }}, 50^{\text {th }}, 90^{\text {th }}$ and $95^{\text {th }}$ percentiles of head circumference $(\mathrm{mm})$ with $95 \%$ confidence of interval $(\mathrm{Cl})$. It also gives estimated mean and \pm 2 standard deviations ( $\pm 2 S D$ ) of the data. The coefficient of multiple correlation $R^{2}=0.975(p<0.001)$, which indicates a good correlation between the two variables. There was gradual increase of \pm 2 standard deviations towards term, from $11.9 \mathrm{~mm}$ to $28.0 \mathrm{~mm}$. Graph 2 (Fig: 4) shows raw data for femur length with fitted, $3^{\text {rd }}, 10^{\text {th }}$, $50^{\text {th }}, 90^{\text {th }}$ and $95^{\text {th }}$ percentiles curves superimposed on it.

Table II: Summary of measurement of head circumference (Observed) $(n=397)$

\begin{tabular}{|l|c|c|c|c|c|c|c|c|}
\hline Weeks & $\begin{array}{c}\text { No. of } \\
\text { fetuses }\end{array}$ & $3^{\text {rd }}$ & $10^{\text {th }}$ & $50^{\text {th }}$ & $90^{\text {th }}$ & $95^{\text {th }}$ & Mean & 2 SD \\
\hline 18 & 17 & 137.6 & 139.2 & 152.0 & 164.8 & 166.4 & 152.00 & 10.2 \\
\hline 19 & 14 & 146.1 & 148.1 & 164.5 & 180.9 & 183.0 & 164.50 & 10.5 \\
\hline 20 & 15 & 157.6 & 159.2 & 172.0 & 184.8 & 186.4 & 172.00 & 10.8 \\
\hline 21 & 17 & 168.5 & 169.9 & 181.5 & 193.1 & 194.6 & 181.50 & 11.2 \\
\hline 22 & 18 & 184.3 & 185.5 & 195.5 & 205.5 & 206.8 & 195.50 & 11.6 \\
\hline 23 & 16 & 195.4 & 196.8 & 208.0 & 219.2 & 220.6 & 208.00 & 12.0 \\
\hline 24 & 14 & 201.9 & 203.7 & 218.5 & 233.3 & 235.2 & 218.50 & 12.3 \\
\hline 25 & 17 & 215.6 & 217.2 & 230.0 & 242.8 & 244.4 & 230.00 & 12.6 \\
\hline 26 & 18 & 210.5 & 212.9 & 232.5 & 252.1 & 254.6 & 232.50 & 12.9 \\
\hline 27 & 18 & 231.1 & 233.2 & 250.0 & 266.8 & 268.9 & 250.00 & 13.3 \\
\hline 28 & 19 & 235.2 & 237.3 & 254.5 & 271.7 & 273.9 & 254.50 & 13.6 \\
\hline 29 & 20 & 245.0 & 247.0 & 263.0 & 279.0 & 281.0 & 263.00 & 13.9 \\
\hline 30 & 20 & 262.9 & 264.8 & 280.0 & 295.2 & 297.1 & 280.00 & 14.4 \\
\hline 31 & 21 & 265.4 & 267.7 & 286.5 & 305.3 & 307.7 & 286.50 & 14.7 \\
\hline 32 & 20 & 269.5 & 272.0 & 292.0 & 312.0 & 314.5 & 292.00 & 15.0 \\
\hline 33 & 22 & 285.9 & 287.8 & 303.0 & 318.2 & 320.1 & 303.00 & 15.3 \\
\hline 34 & 22 & 290.0 & 291.9 & 307.5 & 323.1 & 325.1 & 307.50 & 15.7 \\
\hline 35 & 23 & 288.3 & 290.6 & 309.0 & 327.4 & 329.7 & 309.00 & 16.0 \\
\hline 36 & 23 & 296.9 & 299.7 & 322.5 & 345.3 & 348.2 & 322.50 & 16.4 \\
\hline 37 & 21 & 305.1 & 307.2 & 324.0 & 340.8 & 342.9 & 324.00 & 16.7 \\
\hline 38 & 22 & 303.3 & 305.6 & 324.0 & 342.4 & 344.7 & 324.00 & 27.1 \\
\hline & & & & & & & \\
\hline
\end{tabular}

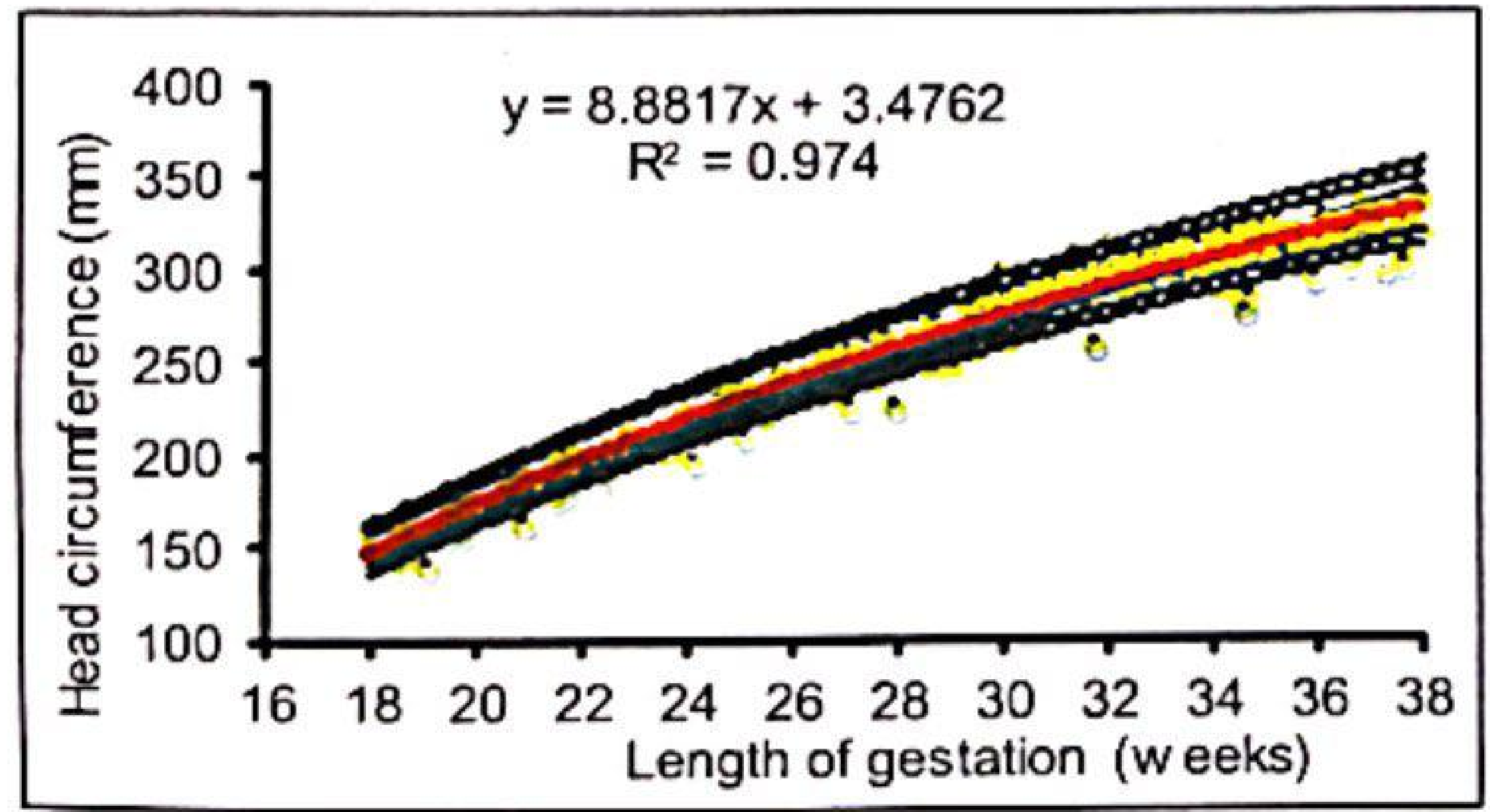

Fig 4: Raw data for head circumference with fitted $3^{\text {tr }}, 10^{\text {th }}, 50^{\text {th }}, 90^{\text {th }}$ and $95^{\text {th }}$ percentiles $(r=0.987)$
Fitted percentiles of head circumference (HC) $(\mathrm{mm})$. Estimated values.

Table III shows the regression of best fit is given when $a=-0.0499, b=9.667$ and $c=-$ 100.39. Where $a$ and $b$ coefficient $c$ is constant. The form of quadratic quadratic equation of regression is given by $y=a w^{2}+b w+c$. Here, $w=i n d e p e n d e n t$ variable (gestational age) and $y$ is dependent variable (Head circumference). Substituting the values for $a, b$ and $c$ into this form gives the equation for the quadratic function best fitting the data set.

$$
y=-100.39+9.6667 w-0.0499 w^{2}
$$

Table III : Fitted percentiles of head circumference (estimated)

\begin{tabular}{|c|c|c|c|c|c|c|c|c|}
\hline Weeks & $\begin{array}{c}\text { No. of } \\
\text { fetuses }\end{array}$ & $3^{\text {rd }}$ & $10^{\text {th }}$ & $50^{\text {th }}$ & $90^{\text {th }}$ & $95^{\text {th }}$ & Mean & 2 SD \\
\hline 18 & 17 & 137.3 & 138.7 & 149.9 & 161.1 & 162.5 & 149.9 & 15.8 \\
\hline 19 & 14 & 149.5 & 150.9 & 162.3 & 173.7 & 175.2 & 162.3 & 17.4 \\
\hline 20 & 15 & 160.1 & 161.6 & 173.4 & 185.3 & 186.8 & 173.4 & 15.5 \\
\hline 21 & 17 & 172.8 & 174.3 & 186.5 & 198.7 & 200.3 & 186.5 & 13.5 \\
\hline 22 & 18 & 183.8 & 185.4 & 198.1 & 210.8 & 212.4 & 198.1 & 13.5 \\
\hline 23 & 16 & 195.7 & 197.4 & 210.4 & 223.5 & 225.2 & 210.4 & 15.2 \\
\hline 24 & 14 & 205.5 & 207.2 & 220.6 & 234.1 & 235.8 & 220.6 & 18.2 \\
\hline 25 & 17 & 216.1 & 217.8 & 231.6 & 245.4 & 247.2 & 231.6 & 15.8 \\
\hline 26 & 18 & 226.4 & 228.2 & 242.2 & 256.1 & 257.9 & 242.2 & 18.4 \\
\hline 27 & 18 & 235.3 & 237.1 & 251.5 & 265.9 & 267.7 & 251.5 & 19.0 \\
\hline 28 & 19 & 244.6 & 246.4 & 261.2 & 276.1 & 277.9 & 261.2 & 19.4 \\
\hline 29 & 20 & 253.9 & 255.8 & 270.8 & 285.8 & 287.7 & 270.8 & 20.8 \\
\hline 30 & 20 & 262.7 & 264.7 & 280.2 & 295.7 & 297.6 & 280.2 & 19.7 \\
\hline 31 & 21 & 269.9 & 271.9 & 287.8 & 303.8 & 305.7 & 287.8 & 21.6 \\
\hline 32 & 20 & 277.4 & 279.4 & 295.6 & 311.8 & 313.8 & 295.6 & 24.4 \\
\hline 33 & 22 & 283.9 & 285.9 & 302.5 & 319.0 & 321.0 & 302.5 & 18.5 \\
\hline 34 & 22 & 290.7 & 292.9 & 310.0 & 327.2 & 329.3 & 310.0 & 19.5 \\
\hline 35 & 23 & 296.3 & 298.4 & 315.8 & 333.2 & 335.4 & 315.8 & 22.1 \\
\hline 36 & 23 & 301.0 & 303.2 & 321.0 & 338.8 & 341.0 & 321.0 & 25.1 \\
\hline 37 & 21 & 305.1 & 307.3 & 325.4 & 343.4 & 345.7 & 325.4 & 21.2 \\
\hline 38 & 22 & 308.3 & 310.6 & 329.0 & 347.4 & 349.7 & 329.0 & 23.2 \\
\hline
\end{tabular}

Fitted model Head Circumference

Mean $=-100.39+9.6667 w-0.0499 w^{2}$

$\mathrm{SD}=5.6845+0.4850 \mathrm{w}$

$R^{2}=0.975 \quad(p<0.001)$

Correlation Between gestational age measured by LMP with estimated gestational age evaluated by head circumference ( $n=397$ : Gestational age was calculated by LMP of 397 cases and expressed in weeks. Estimated gestational was determined by head circumference evaluated by ultra sonogram and expressed in weeks. Significant positive correlations was 
found between gestational age measured by LMP with estimated gestational age evaluated by head circumference.

The values of Pearson's correlation coefficient was 0.994 which is highly significant $(p<0.001)$. Therefore, there was linear positive correlation between gestational age measured by LMP with estimated gestational age evaluated by head circumference (Figure 5). Measured by LMP with estimated gestational age evaluated by head circumference.

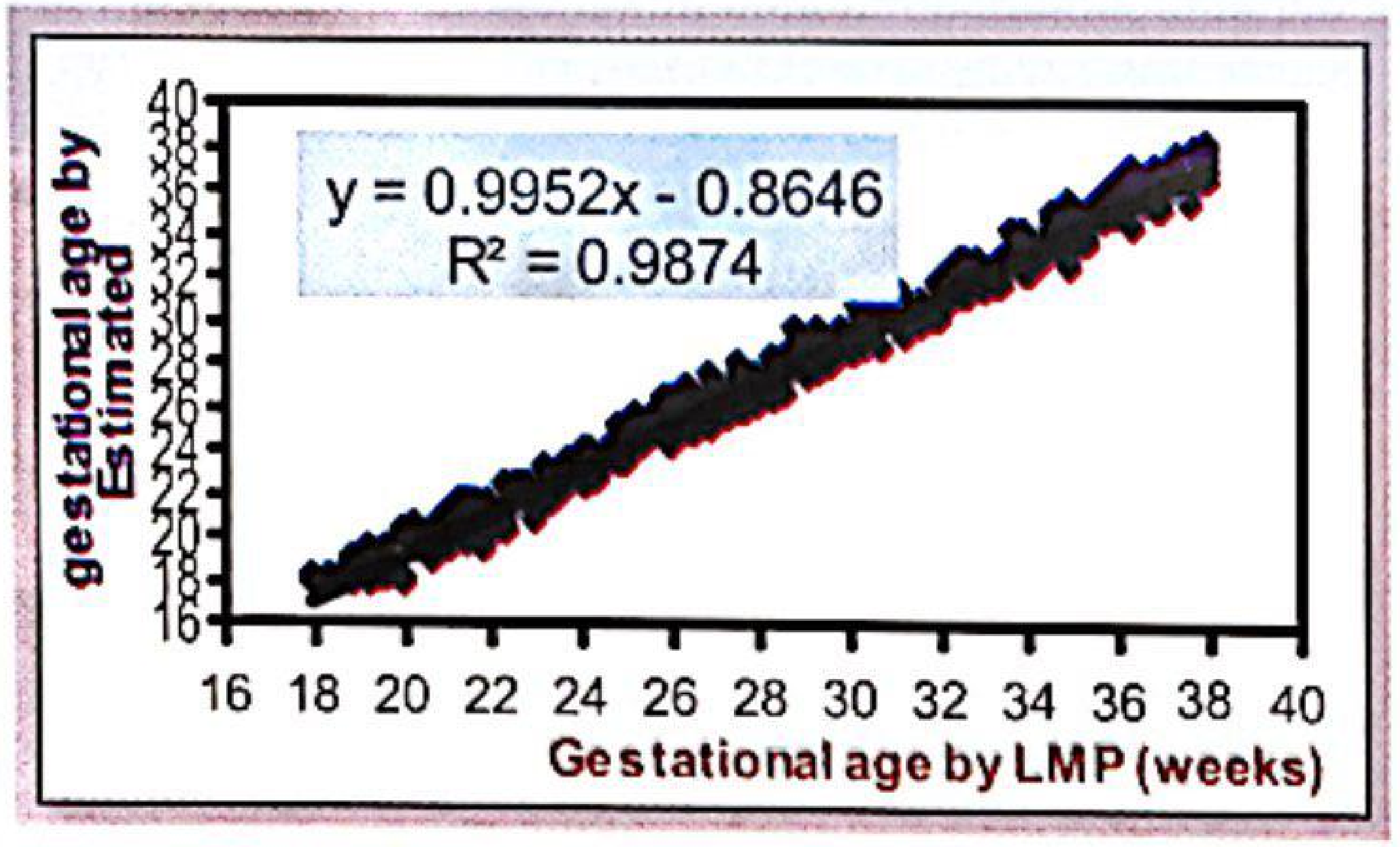

Fig.5: The scatter diagram shows significant relationship ( $r=0.994)$ between gestational age

\section{Discussion}

Ultrasound is a non invasive diagnostic procedure and there is no scientific evidence of any deleterious biologic effects from ultrasound on the developing fetus. Determination of gestational age by ultrasound has become an integral part of maternal antenatal care. Accurate assessment of gestational age by sonography can be of great importance in management decisions during pregnancy. For example, timing of elective cesarean delivery and the decision whether to consider a fetus at risk for intrauterine growth retardation depend in part on the estimated age.

Fetal head measurements have been demonstrated to be important in assessing fetal age, in plotting fetal growth, and in detecting intrauterine growth retardation, isoimmunization and macrosomia. ${ }^{8}$ Biparietal diameter (BPD) is only single dimension of head and is frequently not truly representative of total head and brain size. The narrow BPD gives a false impression of subnormal head size. Head circumference measurement is more representative of brain size even in normal weight dolichocephalic fetuses.

Accuracy of gestational age estimation by $\mathrm{HC}$ measurement is comparable with that of BPD measurement. However, in fetuses with abnormal head shape, either brachycephaly or dolicocephaly, HC may be a more accurate predictor of fetal age than BPD. ${ }^{5}$

The accuracy of each predictor of gestational age worsens progressively as pregnancy proceeds. The corrected BPD and the $\mathrm{HC}$ are equally accurate at all stages and both are more accurate than is the BPD. ${ }^{6}$

Accuracy of fetal age predictions using the BPD in third trimester is somewhat limited. Variation of BPD increases while there is change of head shape like dolichocephaly or brachycephaly and can be associated with breech fetuses, multiple pregnancy or oligohydramnios. ${ }^{9}$ In such situation BPD would be falsely small or large while Head circumference $(\mathrm{HC})$ will remain unaltered, therefore providing a better indication of the real as compared with the apparent size of the fetal head. So $\mathrm{HC}$ is more accurate guide to the gestational age in late pregnancy. ${ }^{12}$

The male fetuses have significantly larger $\mathrm{HC}$ and BPD measurement compared to female fetuses. These prenatal sex-related differences are established by as early as 16 weeks of gestation and tend to increase with advancing gestational age. ${ }^{10}$

In Hadlock chart/table it was found that estimated gestational age measured from $\mathrm{HC}$ had very close relation with weeks of gestation(LMP), which is 2 to 3 days less from weeks of gestation (LMP) during 18-38 weeks. ${ }^{11}$

Law measured the head circumference of 594 fetuses and femur length. ${ }^{12}$ In a statistically significant proportion of cases, the head circumference was more closely related than the biparietal diameter to both the Femur length and the gestational age of the fetus as calculated from the mothers menstrual history. It was observed in the study that the head circumference is a more accurate index of the 
age of the fetus and its growth potential then is the biparietal diameter and that use of the head circumference should replace that of the biparietal diameter in obstetric scanning. ${ }^{12}$

All these findings suggest that ultrasonologists should use the fetal biometry which is originated from the same population. Until now the sonographers of our country are using the measurement parameters of Japanese standard to calculate the period of gestation and to assess the fetal growth as no fetal growth chart of this country is so far available .The hypothesis test result indicates that the gestational age and gestational age measured by head circumference of our population better corresponds to menstrual age. ${ }^{13}$

\section{Conclusion}

Ultrasound is the best and safest modality to obtain information about the fetus and its environment directly and is an accurate method for determining the gestational age. Method of gestational age estimation that take head shape into account are more accurate than method using BPD alone in the second trimester. This data suggest that this is true in the third trimester as well as also useful in second trimester, but studies with more third trimester cases would be needed to confirm this. While the three methods considered appear to be equally accurate, area correction---based on convenience and theoretical consideration may be the preferred approach. It is easy to apply and can be used in conjunction with any formula. However, the number of cases in this study is limited. So to establish head circumference $(\mathrm{HC})$ of fetuses standard in Bangladesh a bigger patient population study is required.

\section{References}

1. Campbell AS, Warsof SL, Little D,Cooper $D J, R o u t i n e$ ultrasound screening for prediction of gestational age. Obstet Gynaecol 1985;65:613-620.

2. Nisa, L., Hassan, M., Moslem, F. 1996, 'Gestational age determination'. Bangladesh J Uitrasonography, Vol.3,pp.198-199.
3. Moslem F, Latifa S, Iffatara B et al. Relation of $B P D$ with gestational age in Bangladeshi fetus Bangladesh J Ultrasonography, 1996;3:3-8.

4. Hadlock,FP. Detter, RL. Harrist. RB, Park, SK,1984, Estimating foetal age: Computer Assisted analysis of multiple fetal growth parameters, Radiology, 1984;Vol.152, pp.497501.

5. Scott-N.MacGregor,Assistant Professor, Department of Obstetrics and Gynecology, Northwestern University Medical School, Chicago; Evanston Hospital, Evanston, Illinois.

6. Carol B,Benson Peter M, Doublet, Sonographic Prediction of Gestational Age:Accuracy of second and third-Trimester Fetal Measurements. AJR 157:1275-1277, December 1991.

7. Hadlock FP, Deter RL, Ronald B. Harrist, Seung K. Park, 'Fetal Head Circumference: Relation to Menstrual Age, 'AJR 1982;138,pp 649-653.

8. Hadlock, FP. Kent, WR.,Loyd, JL., Harrist, RB. Deter, RL., Park. SK, 1982, An evaluation of two methods for measuring fetal Head and Body circumference, ' $J$ ultrasound in medicine'. Vol. 1. $p p$ 359-360.

9. Dey, SK, Sobhan, S \& Rahman, MH.2004, 'Importance of cephalic index in gestational age calculation'. An ultrasound study of 265 pregnancies'. Bangladesh ultrasonography. Vol. 11, No.1, pp. 9-11.

10. Lubusky M, Mickova I, Prochazka M, Dzvincuk $P$, Mala K, Cizek L, "Discrepancy of ultrasound biometric parameters of the head ( $H C, B P D)$ and $F L$ in relation to sex of the fetus and duration of pregnancy". Ces Gynek 2006; 71:169-72.

11. Hadlock FP, Deter RL, Roecher E et al. Relation of fetal femur length to neonatal crown-heel length. J Ultrasound Med 1984;3:1.

12. Law, RG., MacRea,KD.1982, 'Head circumference is a index of fetal age'. $J$ ultrasound in medicine, Vol 1, pp.281-288.

13. Campbell $S$, Thomas A. Uitrasound measurement of the fetal head to abdomen Circumference ratio in the assessment of growth retardation. $\mathrm{Br} J$ Obstet Gynaecol 1977;84:165-174. 